\title{
The laparoscopy splenic injury repair. The use of fibrin glue in a heparinized porcine model ${ }^{1}$
}

\author{
O reparo de lesão esplênica por laparoscopia. O uso da cola de fibrina \\ em porcos heparinizados
}

\author{
Dalmer Faria Freire', Murched Omar Taha ${ }^{I I}$, José Homero Soares ${ }^{\mathrm{III}}$, Manoel de Jesus Simões ${ }^{\mathrm{IV}}$, Anna Luiza Negrini Fagundesv, \\ Djalma José Fagundes ${ }^{\text {VI }}$
}

${ }^{1}$ Research performed at the Surgery and Experimentation Postgraduate Program, Federal University of Sao Paulo (UNIFESP), Brazil. Part of Master's degree thesis. Mentor: Omar Taha Murched.

${ }^{I}$ MSc, Head Coordinator of Surgery Residence, Campo Limpo County Hospital, Sao Paulo, Brazil. Responsible for design, intellectual and scientific content of the article.

${ }^{\text {II }} \mathrm{PhD}$, Affiliate Professor, Surgical Techniques and Experimental Surgery Division, Surgery Department, UNIFESP, Sao Paulo, Brazil. Conception, design, analysis, interpretation of data and critical review.

III PhD, Affiliate Professor, Surgical Techniques and Experimental Surgery Division, Surgery Department, UNIFESP, Sao Paulo, Brazil. Acquisition of data, helped with technical procedures and statistical analysis.

IV PhD, Associate Professor, Morphological Department, UNIFESP, Sao Paulo, Brazil. Histopathologic examinations, acquisition of data and critical revision.

${ }^{\vee}$ Graduate Student, University of Santo Amaro, Scientific Initiation Fellowship, Sao Paulo, Brazil. Helped with technical procedures, collection of informations and responsible for English language.

${ }^{\mathrm{VI}} \mathrm{PhD}$, Associate Professor, Surgical Techniques and Experimental Surgery Division, Surgery Department, UNIFESP, Sao Paulo, Brazil. Conception, design, critical revision and manuscript writing.

\section{ABSTRACT}

Purpose: To investigate the effectiveness of fibrin glue (laparoscopic via) into promote the hemostasis of a spleen injury on a heparinized porcine model. Methods: Eighteen Landrace porcine were submitted to laparoscopic spleen injury and randomly distributed: GHA (heparin plus adhesive), GH (heparin without adhesive) and GS (Sham - without heparin or adhesive). Ten minutes before the surgical procedures a single IV dose (200UI/kg) of heparin sodium was administrated only to groups GHA and GH. In the GHA, adhesive was applied after the mechanical injury and recorded the time until the polymerization and clot formation. Results: No significant differences occurred among the groups (Fisher test) considering the weight and surgery time. The blood amount in the abdominal cavity on GH was significantly higher in comparison to the sham group and especially with the GHA $(\mathrm{p}<0.004)$. No significant differences were observed in the body temperature, heart rate, cardiac output, means arterial pressure, pulmonary artery pressure during the experiment. The activated partial thromboplastin time (APTT) was lower in the GHA in comparison to GH ( $<<0.003$ ). Conclusion: The fibrin biological adhesive applied by laparoscopy is effective for hemostasis of minor spleen injury in a porcine model under the effect of anticoagulant drug.

Key words: Splenic Rupture. Fibrin Tissue Adhesive. Laparoscopy. Hemostasis, Surgical. Rabbits.

\section{RESUMO}

Objetivo: Investigar a eficácia da cola de fibrina (via laparoscópica) na hemostasia de uma lesão no baço de porco heparinizado. Métodos: Dezoito suínos Landrace foram submetidos a lesão do baço e distribuídos aleatoriamente: GHA (heparina adesivo), GH (heparina sem adesivo) e GS (Sham - sem heparina ou adesivo). Dez minutos antes dos procedimentos uma dose única (200UI/kg) de heparina sódica (EV) foi administrada nos grupos GHA e GH. A fibrina (GHA) foi aplicada após a lesão e registrado o tempo até a polimerização e formação do coágulo. Resultados: Não houve diferenças significativas entre os grupos (teste de Fisher), considerando o peso e o tempo de cirurgia. A quantidade de sangue na cavidade abdominal de GH foi significativamente maior em comparação ao GS e, especialmente, com o GHA ( $<<0,004)$. Não foram observadas diferenças significativas na temperatura corporal, frequência cardíaca, débito cardíaco, pressão arterial ou pressão da artéria pulmonar durante o experimento (20 minutos). O tempo de tromboplastina parcial ativada (TTPA) foi menor no GHA em relação ao GH $(\mathrm{p}<0,003)$. Conclusão: A cola de fibrina biológica aplicada por laparoscopia é eficaz para a hemostasia de lesões no baço menor em um modelo suíno sob o efeito de drogas anticoagulantes.

Descritores: Ruptura Esplênica. Adesivo Tecidual de Fibrina. Laparoscopia. Hemostasia Cirúrgica. Coelhos. 


\section{Introduction}

The spleen is currently injured in the abdominal trauma, but was well know the relationship between splenectomy and increased occurrence of infections ${ }^{1}$.

Thereafter, several surgical procedures to preserve the injured spleen were proposed, most of them using the laparotomy via, using surgical sutures and ligatures to the vascular pedicle and other topic haemostatic maneuvers. However, these procedures involved the use of surgical thread or foam that acting as foreign bodies and promote local inflammatory reaction and hinders the healing process ${ }^{1}$. Furthermore, the sutures are difficult by the soft and friable consistency of spleen parenchyma.

The treatment of these injuries with biological adhesive seems to be advantageous to avoid the use of sutures or foam, the compound is completely absorbed in a few days ${ }^{2}$ and is not associated to foreign body granuloma ${ }^{3}$.

The biological adhesive of fibrin allowed a new approach to the bleeding spleen trauma, initially by laparotomy ${ }^{4}$, and recently by laparoscopic via ${ }^{5}$. The polymerization of the adhesive is effective independently of the integrity of the coagulation cascade or the platelets count, and this may be an advantage in patients with coagulopathy diseases or under the effect of anticoagulant $\operatorname{drugs}^{6,7}$.

Our purpose is verifying the effectiveness of fibrin glue, used by laparoscopic via, in comparison to the conventional suture into promote the hemostasis of a standard spleen injury on a heparinized experimental porcine model.

\section{Methods}

The experimental protocol (\#1364/07) was approved by the Ethics Committee of the Federal University of Sao Paulo (UNIFESP), Brazil. The pigs were maintained according to the norms of the Guide for the Care and Use of Laboratory Animals (Institute for Laboratory Animal Research, 1996) and to the ethical principles of the Brazilian Committee on Animal Experimentation (COBEA).

Eighteen Landrace pigs, males, six months old, weighing 14 to $19.5 \mathrm{~kg}$ each were housed in temperature - and lightcontrolled environmental conditions with a 12-hour light-dark cycle, and given free access to water and standard pellet chow until 6 hours prior the surgical procedures. All procedures were done in the laboratories of Experimental Surgery, Department of Surgery (UNIFESP). The animals were submitted to laparoscopic standard spleen injury and randomly distributed in three groups $(n=6)$ :
GHA (heparin plus adhesive), GH (heparin without adhesive) and GS (Sham - without heparin or adhesive).

After six hours fasting for solid diet and four hours for liquid diet, the animals received intramuscularly $0.2 \mathrm{mg} / \mathrm{kg}$ of acepromazin and $0.75 \mathrm{mg} / \mathrm{kg}$ of midazolan. Ten minutes later, they received $10 \mathrm{mg} / \mathrm{kg}$ intravenously of sodium thiopental. The anesthesia was maintained by endotracheal probe (Rush 7) with oxygen and $1 \%$ halothane. Ringer lactate was administrated intravenously at rate of $500 \mathrm{ml} /$ hour.

A left cervical incision allowed inserting a $6 \mathrm{~F}$ catheter in the left carotid artery for measures of mean arterial pressure (MAP) and heart rate (HR) using Phillips Viridia 4C device (Phillips Healthcare). A Swan-Ganz catheter (Edwards Lifesciences LLC - Irvine, CA USA), was inserted in the internal jugular vein and guided to the pulmonary artery for monitoring the body temperature $(\mathrm{T})$, the pulmonary artery pressure (PAP) and cardiac output (CD). Vascular blood samples were collected to determine the activated partial thromboplastin time (APTT).

Ten minutes before the beginning of the surgical procedures a single dose $(200 \mathrm{UI} / \mathrm{kg}$ ) of heparin sodium, was intravenously administrated in the animals of groups GHA and GH. The animals of GS were not heparinized.

Under aseptic conditions the laparoscopic standard procedure was performed in the animals of all groups. A Veress needle was inserted in the umbilical region and the pneumoperitoneum was setting up a pressure of $12 \mathrm{~mm} \mathrm{Hg}$. The needle was withdrawn and inserted into this place a $10 \mathrm{~mm}$ trocar and the $30^{\circ}$ optical set.

Six centimeters from the abdominal middle line and three centimeters below the left costal margin a second trocar $(10 \mathrm{~mm})$ was inserted and used to make way for the mechanical device specially designed (Figure 1) to produce a standardized circular injury half centimeter in diameter and one and half centimeter deep in the spleen parenchyma. It consisted of a core of round surgical steel with pointed end that was triggered by an internal spring. To arm the device was pulled to the upper end of inner rod until the point of locking. The release of the trigger attached to the outer end was enough to push the steel blade with standard power toward and then producing the spleen injury.

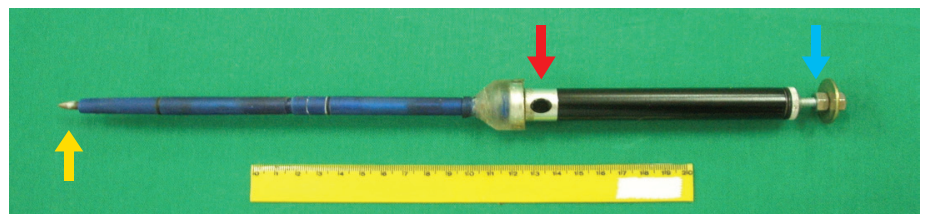

FIGURE 1 - Device used to promote the spleen injury. Steel blade end point (yellow arrow). Trigger (red arrow). Bar to arm the internal spring (blue arrow). 
A third trocar $(5 \mathrm{~mm})$ was introduced ten centimeters from the left of the midline and ten centimeters below the left costal margin by which introduces a forceps (grasper). The purpose of this clamp was to improve the visualization of the spleen in order to perform the spleen injury.

Only in the animals of GHA a fourth trocar $(5 \mathrm{~mm})$ was inserted three centimeter from the middle line and five centimeters below the left costal margin to allowed the passage of doublelumen cannula in which were attached two syringes (Figure 2). The syringe $\mathrm{A}(0.5 \mathrm{~mL})$ contained a mixture of fibrinogen, aprotinin and factor XIII, and syringe $\mathrm{B}(0.5 \mathrm{~mL})$ a mixture of thrombin and calcium chloride. The biological adhesive was composed of fibrinogen $(65-115 \mathrm{mg} / \mathrm{mL})$, factor XIII (40-80 U/mL), aprotinin (1000 UIC/mL), thrombin (400-600 IU/mL) and calcium chloride $(5.88 \mathrm{mg} / 0.5 \mathrm{~mL})$. It was preserved at 4 degrees centigrade, being brought to room temperature for 30 minutes before its application in spleen injury. Fibrin glue was applied immediately after the mechanical injury and recorded the time elapsed until the polymerization and clot formation.

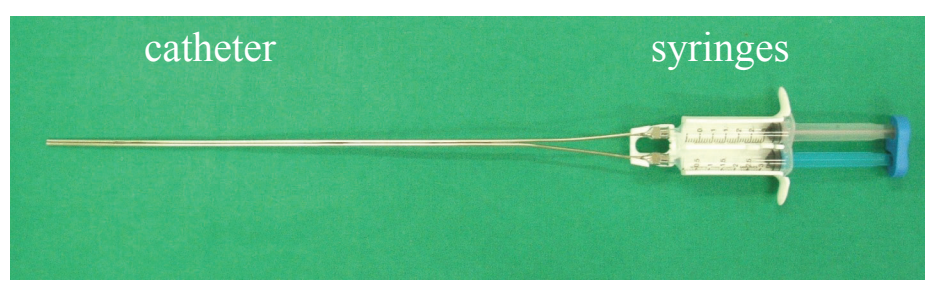

FIGURE 2 - The double-lumen cannula in which was attached two syringes with the two components of fibrin glue.

The time of the procedure was recorded from the introduction of the first trocar until the end of laparotomy procedure.

The animals were monitoring during 20 minutes immediately after the spleen injury (T0), ten minutes (T10) and 20 minutes (T20) after the injury. It were recording the mean arterial pressure (MAP), heart rate (HR), body temperature (T), pulmonary artery pressure (PAP) and activated partial thromboplastin time (APTT).

After T20 was performed medium laparotomy in animals of all groups. To estimate the blood loss during the period of twenty minutes of observation, the amount of blood collected in the abdominal cavity was carefully drained with dry gauze. For each gram of the weight (difference between dry and wet weight of the gauze) was considered as the loss of a milliliter of blood.

The gross aspects of spleen injury and the fibrin clot was evaluated and photographed. The spleen was collected for further microscopic study.
The animals were euthanized by the administration of $10 \mathrm{~mL}$ of potassium chloride intravenously.

For light microscopy samples involving the injury and peripheral area were fixed in 10\% formalin, immersed in paraffin, and stained with hematoxylin-eosin (HE). Histological evaluations were performed with light microscope (Axiolab Standard 2.0, Carl Zeiss) in magnification of 10X, 100X and 200X.

For data analysis, it was used the statistical software SPSS version 15.0 for Windows. The $\mathrm{p}<0.05$ or $5 \%$ was considered statistically significant. The descriptive analysis of continuous variables was described by mean and standard deviation. Categorical variables were described in a contingency table containing the frequency and percentage of occurrences in each group and time. For the inferential analysis were applied the following nonparametric statistical tests: Kruskal-Wallis test to verify the hypothesis of equality between the three groups; MannWhitney, to check the equality of groups 2 to 2, when applied, using the Kruskal-Wallis test, it appears that the 3 groups were not equal; Friedman test, when it wanted to verify the hypothesis that the results of each animal did not change at any time (3 or more repeated measures); Wilcoxon test to verify the equal time 2 to 2 , when applied, using the Friedman test, it appears that the 3 times were not all alike; Fisher's generalized test: suitable for frequency tables, with which it tested the hypothesis that the observed frequencies in the categories were distributed evenly between the groups. 


\section{Results}

Our data were exposed in the following tables and figures.

TABLE 1 - The means and standard deviation of weight $(\mathrm{kg})$, elapsed time of surgical procedures (minutes) and blood loss $(\mathrm{mL})$ in the animals of GHA (heparin plus adhesive), GH (heparin only) and GS (without heparin or adhesive). No significant differences among the groups (Fisher test) considering the weight and surgery elapsed time. The blood amount in the abdominal cavity on GH was significantly higher in comparison to the sham group and especially with the GHA $(\mathrm{p}<0.004)$.

\begin{tabular}{cccc}
\hline Groups & $\begin{array}{c}\text { Weight } \\
(\mathrm{kg})\end{array}$ & $\begin{array}{c}\text { Surgery time } \\
(\mathrm{min})\end{array}$ & $\begin{array}{c}\text { Blood loss } \\
(\mathrm{mL})\end{array}$ \\
\hline GHA & $15.4( \pm 0.9)$ & $46.8( \pm 8.0)$ & $1.8 \pm(0.8)^{\S}$ \\
GH & $16.9( \pm 2.4)$ & $39.5( \pm 6.1)$ & $6.8 \pm(4.4)$ \\
GS & $16.7( \pm 1.1)$ & $42.8( \pm 7.2)$ & $3.0 \pm(1.1)$ \\
\hline $\mathrm{p}$ & $\mathrm{p}=0.332$ & $\mathrm{p}=0.294$ & $\S \mathrm{p}=0.004$ \\
\hline
\end{tabular}

TABLE 2 - Distribution (means and standard deviation) of body temperature (centigrade) in the periods T0 (beginning of surgical procedures), T10 (ten minutes after), T20 (20 minutes after) in the animals of GHA (heparin plus adhesive), GH (heparin only) and GS (without heparin or adhesive). There are no significant differences (Kruskal-Wallis test) among the groups and no significant differences (Friedman and Wilcoxon tests) among the elapsed times, except in GHA on T20 ( $p=0.009)$.

\begin{tabular}{|c|c|c|c|c|}
\hline & $\begin{array}{c}\text { TO } \\
\text { (min) }\end{array}$ & $\begin{array}{c}\text { T10 } \\
\text { (min) }\end{array}$ & $\begin{array}{c}\text { T20 } \\
\text { (min) }\end{array}$ & p \\
\hline GHA & $35.5 \pm 1.1$ & $35.3 \pm 1.1$ & $35.1 \pm 1.2$ & $\mathrm{p}=0.099$ \\
\hline GH & $35.9 \pm 0.7$ & $35.7 \pm 0.9$ & $35.7 \pm 0.9$ & $\mathrm{p}=0.172$ \\
\hline GS & $35.7 \pm 0.9$ & $\begin{array}{c}35.6 \\
\pm 1.06\end{array}$ & $35.5 \pm 1.2$ & $\mathrm{p}=0.119$ \\
\hline $\mathbf{p}$ & $\mathrm{p}=0.082$ & $\mathrm{p}=0.073$ & $\mathrm{p}=0.065$ & \\
\hline
\end{tabular}

TABLE 3 - Distribution (means and standard deviation) of mean heart rate (beat/min) in the periods T0 (beginning of surgical procedures), T10 (ten minutes after), T20 (20 minutes after) in the animals of GHA (heparin plus adhesive), GH (heparin only) and GS (without heparin or adhesive). No significant differences (Kruskal-Wallis test) were detected among the groups, except on T0 ( $\mathrm{p}=0.039)$; no significant differences (Friedman and Wilcoxon tests) among the elapsed times.

\begin{tabular}{|c|c|c|c|c|}
\hline & $\begin{array}{c}\text { TO } \\
\text { (min) }\end{array}$ & $\begin{array}{c}\text { T10 } \\
\text { (min) }\end{array}$ & $\begin{array}{c}\text { T20 } \\
\text { (min) }\end{array}$ & $\mathbf{P}$ \\
\hline GHA & $\begin{array}{l}109.0 \\
\pm 18.5\end{array}$ & $\begin{array}{l}115.3 \\
\pm 34.1\end{array}$ & $\begin{array}{r}118.5 \\
\pm 38.2\end{array}$ & $\mathrm{p}=0.846$ \\
\hline GH & $\begin{array}{l}148.0 \\
\pm 40.4\end{array}$ & $\begin{array}{l}147.7 \\
\pm 46.8\end{array}$ & $\begin{array}{l}152.7 \\
\pm 51.7\end{array}$ & $\mathrm{p}=0.513$ \\
\hline GS & $\begin{array}{r}100.0 \\
\pm 16.0 \\
\end{array}$ & $\begin{array}{r}111.8 \\
\pm 17.5 \\
\end{array}$ & $\begin{array}{r}111.3 \\
\pm 22.0 \\
\end{array}$ & $\mathrm{p}=0.042$ \\
\hline $\mathbf{p}$ & $\mathrm{p}=0.039$ & $\mathrm{p}=0.346$ & $\mathrm{p}=0.235$ & \\
\hline
\end{tabular}

TABLE 4 - Distribution (means and standard deviation) of cardiac output ( $\mathrm{L} / \mathrm{min}$ ) in the periods $\mathrm{T} 0$ (beginning of surgical procedures), T10 (ten minutes after), T20 (20 minutes after) in the animals of GHA (heparin plus adhesive), GH (heparin only) and GS (without heparin or adhesive). No significant differences (Friedman test) among the elapsed times in the GHA, but significant decrease in T20 of the GH and decrease in T10 and T20 of the GS. No significant difference (Friedman test) among the groups in $\mathrm{T} 0$.

\begin{tabular}{ccccc}
\hline & $\begin{array}{c}\text { TO } \\
(\mathbf{m i n})\end{array}$ & $\begin{array}{c}\text { T10 } \\
(\mathbf{m i n})\end{array}$ & $\begin{array}{c}\text { T20 } \\
(\mathbf{m i n})\end{array}$ & $\mathbf{p}$ \\
\hline GHA & $3.3 \pm 0.38$ & $3.4 \pm 0.23$ & $3.3 \pm 0.41$ & $\mathrm{p}=0.52$ \\
GH & $3.4 \pm 1.00$ & $3.1 \pm 0.63$ & $2.8 \pm 0.56$ & $\mathrm{p}=0.11$ \\
GS & $3.5 \pm 1.24$ & $3.6 \pm 0.82$ & $3.4 \pm 1.11$ & $\mathrm{p}=0.62$ \\
\hline $\mathbf{p}$ & $\mathrm{p}=0.810$ & $\mathrm{p}=0.280$ & $\mathrm{p}=0.911$ & \\
\hline
\end{tabular}


TABLE 5 - Distribution (means and standard deviation) of mean arterial pressure ( $\mathrm{mm} \mathrm{Hg}$ ) in the periods $\mathrm{T} 0$ (beginning of surgical procedures), T10 (ten minutes after), T20 (20 minutes after) in the animals of GHA (heparin plus adhesive), GH (heparin only) and GS (without heparin or adhesive). There are no significant differences (Kruskal-Wallis test) among the groups and no significant differences (Friedman and Wilcoxon tests) among the elapsed times.

\begin{tabular}{ccccc}
\hline & $\begin{array}{c}\text { TO } \\
(\text { min })\end{array}$ & $\begin{array}{c}\text { T10 } \\
(\mathbf{m i n})\end{array}$ & $\begin{array}{c}\text { T20 } \\
(\mathbf{m i n})\end{array}$ & $\mathbf{p}$ \\
\hline \multirow{2}{*}{ GHA } & 95.8 & 94.0 & 94.7 & $\mathrm{p}=0.910$ \\
& \pm 17.7 & \pm 17.1 & \pm 17.6 & \\
\multirow{2}{*}{ GH } & 89.0 & 90.8 & 87.3 & $\mathrm{p}=1.000$ \\
& \pm 10.7 & \pm 18.3 & \pm 20.0 & \\
\multirow{2}{*}{ GS } & 104.0 & 101.2 & 113.3 & $\mathrm{p}=0.513$ \\
& \pm 21.6 & \pm 20.1 & \pm 28.4 & \\
\hline \multirow{2}{*}{$\mathbf{p}$} & $\mathrm{p}=0.283$ & $\mathrm{p}=0.238$ & $\mathrm{p}=0.128$ & \\
\hline
\end{tabular}

TABLE 6 - Distribution (means and standard deviation) of pulmonary artery pressure $(\mathrm{mm} \mathrm{Hg})$ in the periods $\mathrm{T} 0$ (beginning of surgical procedures), T10 (ten minutes after), T20 (20 minutes after) in the animals of GHA (heparin plus adhesive), GH (heparin only) and GS (without heparin or adhesive). There are no significant differences (Kruskal-Wallis test) among the groups and no significant differences (Friedman and Wilcoxon tests) among the elapsed times.

\begin{tabular}{ccccc}
\hline & $\begin{array}{c}\text { TO } \\
(\text { min })\end{array}$ & $\begin{array}{c}\text { T10 } \\
(\text { min })\end{array}$ & $\begin{array}{c}\text { T20 } \\
(\text { min })\end{array}$ & p \\
\hline GHA & $19.8 \pm 3.4$ & $17.2 \pm 4.2$ & $18.7 \pm 3.1$ & $\mathrm{p}=0.142$ \\
GH & $22.7 \pm 5.6$ & $22.5 \pm 3.8$ & $20.3 \pm 5.9$ & $\mathrm{p}=0.580$ \\
GS & $22.2 \pm 7.1$ & $22.8 \pm 6.1$ & $24.2 \pm 7.7$ & $\mathrm{p}=0.280$ \\
\hline $\mathbf{P}$ & $\mathrm{p}=0.611$ & $\mathrm{p}=0.089$ & $\mathrm{p}=0.134$ & \\
\hline
\end{tabular}
injury (HE - 40X).

\section{Discussion}

Our data has support for the idea that fibrin glue is effective in promoting the repair of a spleen injury in an animal under effect of anticoagulant substance. This was evident by the significantly smaller amount of blood collected in the abdominal cavity in the animals in which the injury was treated with the adhesive in comparison to the group that did not receive any treatment.

The treatment of spleen injury is a challenge even in patients without any coagulation disorder. In patients using anticoagulant or thrombolytic therapy, the literature advocates the reversal of anticoagulation followed by emergency splenectomy ${ }^{8}$. 
Since the demonstration of the importance spleen parenchyma to the immunological integrity of the individual, surgical treatment tries to be as conservative as possible while preserving as much spleen tissue as possible ${ }^{1}$.

Laparoscopy has brought an important step in reducing time and trauma surgery, but the suture of the lesion or its packing with haemostatic foam are still not free from technical difficulties or unsatisfactory results ${ }^{9}$. The surgical adhesive fibrin proved to a viable option for making the operative time less and serves as an alternative to suture or foam materials ${ }^{10}$.

Aiming to test the effects of the association of adhesive application through laparoscopy approach in an animal under the action of anticoagulant drug we use a model in medium-size animal like the pig. The morphology aspect of the porcine spleen is similar to the human being as a reliable model. The sample was homogenous since all animals were male and had body weight equivalent (Table 1).

Among the surgical adhesive available fibrin glue was chosen because it does not produce exothermic reaction during the polymerization process, be reabsorbed by the organism without foreign body granulomas formation and stimulates the healing process.

Fibrin glue is results from the action of thrombin on fibrinogen, a reproduction of the last stage of blood coagulation. The reaction is mediated by calcium, and initially forms a soluble and unstable fibrin monomer. With the addition of coagulation factor XIII and aprotinin (a protease bovine inhibitor) it became a insoluble and stable polymer ${ }^{11}$. The clot formed quickly, about 1 to 4 seconds and adheres firmly to the point of injury by crosslinking of fibrin with collagen, serum glycoprotein and plasmatic cells $^{3}$. In 10 minutes the clot gets $70 \%$ of its strength tensile ${ }^{3}$. Our results showed that the fibrin clot had a stable aspect from 3 a 5 seconds. The photomicrography showed the presence of clot within the lesion in four animals and was only on the surface in two other animals, without directly influence the amount of blood collected (Figure 4).

The two components of the adhesive are mixed at room temperature and inserted through the double lumen cannula. Thus, for the animals of GHA the elapsed time was slightly longer, but not significantly from to other two groups (Table 1).

No significantly body temperature was recorded (Table 2), except a mild decrease on T20 in the GHA, although no attempt was made to keep the temperature of the animals at $37^{\circ} \mathrm{C}$. It is well known that the blood clot formation is delayed when the temperature is below $37^{\circ} \mathrm{C}^{12}$, as result of inhibition of enzymatic reactions of the coagulation cascade induced by hypothermia ${ }^{13}$. The body temperatures in all groups were lower of $37^{\circ} \mathrm{C}$, probably due to anesthesia procedures and surgical trauma. Despite the initial temperature be less than $37^{\circ} \mathrm{C}$ there was no significant difference throughout the period of observation (T0, $\mathrm{T} 10$ and T20). We consider that mild hypothermia (GHA/T20) as favorable to our model, since there is report that APTT is increased in these situations ${ }^{14}$. Thus, in addition to the bleeding disorder due to heparin also had hypothermia acting as facilitating factor in the bleeding of spleen injury. Despite hypothermia, fibrin clotted quickly and was effective in producing stop the bleeding.

The device especially designs for promote a standard trauma caused a minor injury in the spleen parenchyma with a mild blood loss. The blood loss estimated in the animals of GH was three times higher than that of animals which was treated with fibrin and two times higher than the control group who did not use the heparin (Table 1). A blood loss, perhaps by short-term observation, was not enough to cause significant hemodynamic disorders. The cardiac rate, means arterial pressure, pulmonary artery pressure showed no significantly differences in either heeding three times (T0, T10 and T20) in each group or even in groups with each other (Tables 3, 5 and 6). The cardiac output (Table 4) had a slight decrease at T10 and T20 in relation to the initial time (T0) in groups with heparin and the control group. In animals that received the fibrin the blood loss was lower and, as expected, there was no change in the cardiac output.

The effectiveness of heparin was confirmed by the determination of APTT which is commonly used for their sensitivity and accuracy (Figure 3). In this study it was found that the dose of heparin used $(200 \mathrm{U} / \mathrm{kg})$ was sufficient to produce an anticoagulant effect in animals of Groups HA and $\mathrm{H}$.

Moreover, the model has some limitations that should be explored in further research. The degree of splenic injury should be applied to produce more severe injuries; the patch should be applied more deeply in the wound; hypothermia should be investigated to determine their actual influence on the results; more severe injuries may cause more severe hemodynamic changes that may influence the clotting ability of the adhesive.

This research opens the possibility of using fibrin glue as an option for conservative treatment of minor splenic injuries in patient with coagulopathy or under the effect of anticoagulant drugs, avoiding the conventional surgical approach of open laparotomy and the use of sutures or sponges. 


\section{Conclusion}

The fibrin biological adhesive applied by laparoscopy is effective for hemostasis of minor spleen injury in a porcine model under the effect of anticoagulant drug.

\section{References}

1. Shen HB, Lu XM, Zheng QC, Cai XT, Zhou H, Fei KL. Clinical application of laparoscopic spleen-preserving operation in traumatic spleen rupture. Chin J Traumatol. 2005;8:293-6.

2. Martin NE, Kim JW, Abramson DH. Fibrin sealant for retinoblastoma: where are we? J Ocul Pharmacol Ther. 2008;24:433-8.

3. Spotnitz WD, Prabhu R. Fibrin sealant tissue adhesive - review and update. J Long Term Eff Med Implants. 2005;15:245-70.

4. Scheele J, Gentsch HH, Matteson E. Splenic repair by fibrin tissue adhesive and collagen fleece. Surgery. 1984;95:6-13.

5. Olmi S, Scaini A, Erba L, Bertolini A, Guaglio M, Croce E. Use of fibrin glue (Tissucol) as a hemostatic in laparoscopic conservative treatment of spleen trauma. Surg Endosc. 2007;21:2051-4.

6. Delgado AV, Kheirabadi BS, Fruchterman TM, Scherer M, Cortez D, Wade CE, Dubick MA, Holcomb JB. A novel biologic hemostatic dressing (fibrin patch) reduces blood loss and resuscitation volume and improves survival in hypothermia coagulopathic swine with grade V lives injury. J Trauma. 2008;64:75-80.
7. Ade Filho M, Santos RS, Costa JR, Puppin AA, Rezende RA, Beltrão GC. Oral surgery with fibrin sealants in patients with bleeding disorders: a case report. J Contemp Dent Pract. 2006;7:106-12.

8. Errando CL, Tatay J, Serrano-Romero A, Gudín-Uriel M, Revert M, Peiró CM.Splenic rupture and haemoperitoneum in a patient with non-compaction of the left ventricular myocardium. Br J Anaesth. 2005;95:358-65.

9. Rescorla FJ, West KW, Engum SA,Grosfeld JL. Laparoscopic splenic procedures in children: experience in 231 children. Ann Surg. 2007;246:683-7.

10. Schmal H, Geiger G. Laparoscopic splenic salvage in delayed rupture by application of fibrin glue in a 10-year-old boy. J Trauma. 2005;58:828-30.

11. Eberhard U, Broder M, Witzke G. Stability of Beriplast P fibrin sealant: storage and reconstituition. Int J Pharm. 2006;313:1-4.

12. Acheson EM, Kheirabadi BS, Deguzman R, Dick EJ Jr, Holcomb JB. Comparison of hemorrhage control agents applied to lethal extremity arterial hemorrhages in swine. J Trauma. 2005;59:865-74.

13. Rajagopalan S, Masha E, Na J, Sessler DI. The effects of mild perioperative hypothermia on blood loss and transfusion requirement. Anesthesiology. 2008;108:71-7.

14. Martini BS, Crissey JM, Deguzman R, Holcomb JB. In vivo bleeding time and in vitro thrombelastography measurements are better indicators of diluitional hypothermia coagulopathy than prothrombine time. J Trauma. 2007;62:1352-9.

\section{Correspondence:}

Dalmer Faria Freire

Rua Nebraska, 53/52

04560-010 São Paulo - SP Brasil

Phone/Fax: (55 11)5041-5282/9119-9573

dalmerfreire@gmail.com
Conflit of interest: none

Financial source: none

Received: November 10, 2010

Review: January 24, 2011

Accepted: February 18, 2011 